\title{
EFEITO DA COMPOSIÇÃO DO SUBSTRATO NO ENRAIZAMENTO DE ESTACAS DE MARACUJAZEIRO AZEDO ${ }^{1}$
}

\author{
PAULO VÍTOR DUTRA DE SOUZA², EDGAR CARNIEL ${ }^{3}$, MÁRIO LUÍS FOCHESATO ${ }^{4}$
}

\begin{abstract}
RESUMO - Testaram-se diferentes proporções vermiculita (V) e casca de arroz carbonizada (CAC) para a composição de substratos, na propagação de maracujazeiro (Passiflora edulis Sims f. flavicarpa Deg.) por estaquia. As estacas apresentavam duas folhas e suas bases foram submersas por 10 segundos em uma solução hidroalcoólica de AIB (1000mg.L $\left.{ }^{-1}\right)$ no momento da instalação do experimento. O experimento transcorreu em casa de vegetação com microaspersão intermitente e obedeceu ao delineamento experimental de blocos casualizados, com 5 tratamentos, que compreenderam as seguintes proporções em volume (100\% V; 75\% V: $25 \%$ CAC; $50 \%$ V: $50 \%$ CAC; $25 \%$ V: $75 \%$ CAC e $100 \%$ CAC). Utilizaram-se 4 repetições e 15 estacas por parcela. No substrato, foram avaliadas as seguintes características: teor total de sais solúveis, pH em água, densidade úmida, densidade seca e curva de retenção de água. Nas estacas, avaliaram-se: a porcentagem de estacas vivas, o número de raízes, de brotos e de folhas remanescentes por estaca, o comprimento e a matéria seca das raízes e dos brotos. A melhor resposta de enraizamento foi obtida pelo substrato formado pelas misturas dos dois componentes, nas proporções de 50\% V: $50 \%$ CAC e $25 \%$ V: $75 \%$ CAC. Termos de indexação: Propagação vegetativa, estaquia, substratos, características físicas, características químicas.
\end{abstract}

\section{GROWING AVERAGE MOISTURE RELEASE CURVE AND CUTTING PROPAGATION OF PASION FRUIT}

\begin{abstract}
The present experiment tested different vermiculite (V) proportions and carbonized rice husks (CRH) over passion fruit (Passiflora edulis Sims f. flavicarpa Deg.) cutting propagation. The cuttings had two leaves treated with $1000 \mathrm{mg} . \mathrm{L}^{-1}$ of indolebutyric acid for 10 seconds. The experiment was conducted under greenhouse conditions with an intermittent micro spraying system. The experimental design was randomized in blocks with 5 different treatments (100\% V; $75 \%$ V: $25 \%$ CRH; $50 \%$ V: 50\% CRH; 25\% V: 75\% CRH; e 100\% CRH), 4 replicas and 15 cuttings per experimental unit. Salinity, $\mathrm{pH}$, bulk density, and moisture release curve of growing average were evaluated. In addition, cuttings were evaluated on survival; roots number, branches and leaves; roots length and dry matter and branches. The obtained data indicate that $50 \% \mathrm{~V}: 50 \% \mathrm{CRH}$ and $25 \% \mathrm{~V}: 75 \% \mathrm{CRH}$ produced the best results for passion fruit cutting propagation.
\end{abstract}

Index Terms: vegetative propagation, cuttings, physical and chemical characteristics of growing average.

\section{INTRODUÇÃO}

O Brasil é o maior produtor mundial de maracujá, tendo produzido, em 2003, cerca de 485.342 toneladas em uma área de 35.000 ha, sendo que praticamente $44 \%$ desta produção foi proveniente de plantios na região Nordeste do País e $41 \%$, na região Sudeste (IBGE, 2005). Na região Sul, apesar da menor expressão em área cultivada, o maracujazeiro tem sido cultivado em pequenas propriedades, com bons rendimentos, constituindo-se, portando, numa alternativa rentável para estas pequenas propriedades.

O maracujazeiro é propagado basicamente por semente, cuja segregação genética não permite a manutenção das características de cultivares; além disso, há carência de fornecedores comerciais de sementes.

A vida útil do maracujazeiro tem diminuído nos últimos anos, em decorrência de problemas sanitários, especialmente pela fusariose. Portanto, a propagação assexual torna-se uma ferramenta útil para a multiplicação de variedades mais tolerantes e que tenham características de maior produtividade, qualidade e uniformidade (Silva et al., 2005).

Conforme Junqueira et al. (2001), a técnica de produção de mudas de maracujazeiro por estaquia em bandejas permite a obtenção de $90 \%$ de estacas aptas para o plantio no campo, se forem tomados certos cuidados fitossanitários durante a propagação. Destaca-se também a importância do uso de substratos apropriados e o uso de auxinas para o enraizamento de estacas (Álvares et al., 2002; Junqueira et al., 2001; Oliveira et al., 2002).

Entende-se como substrato para plantas o meio onde se desenvolvem suas raízes produzidas antes do plantio definitivo
(Kämpf, 2000). O substrato serve de suporte para as plantas, podendo ainda regular a disponibilidade de nutrientes às mesmas. Ele pode ser formado de solo mineral ou orgânico, de um só ou de diversos materiais em mistura.

Para preparar um substrato, é preciso conhecer a qualidade dos materiais que serão empregados na sua composição, a partir do exame de suas propriedades físicas e químicas. Entre as propriedades físicas, destacam-se a densidade, a porosidade e a disponibilidade de água. As propriedades químicas incluem o valor do $\mathrm{pH}$, a capacidade de troca de cátions e a salinidade. Entre os materiais mais freqüentemente utilizados, estão a vermiculita (alta capacidade de retenção de água) e a casca de arroz carbonizada (baixa capacidade de retenção de água) (Fermino, 2003; Kämpf, 2000; Schmitz et al., 2002). $\mathrm{O}$ uso da casca de arroz carbonizada permite um ganho ambiental pelo destino dado ao resíduo da indústria arrozeira, além de ser barato, reduzindo o custo de produção da muda.

O objetivo deste trabalho foi avaliar o enraizamento de estacas de maracujazeiro produzidas sob diferentes percentuais de mistura de vermiculita e casca de arroz carbonizada, para composição de substratos.

\section{MATERIAL E MÉTODOS}

O experimento foi conduzido de abril a junho de 2002, em casa de vegetação no Departamento de Horticultura e Silvicultura da Faculdade de Agronomia da UFRGS, Porto Alegre-RS.

As estacas de maracujazeiro (Passiflora edulis Sims f. flavicarpa Deg.) foram coletadas no mês de abril, no pomar do Setor de Horticultura da Estação Experimental Agronômica da UFRGS,

\footnotetext{
(Trabalho 095-2005). Recebido: 03-06-2005. Aceito para publicação: 30-05-2006.

${ }^{2}$ Eng. Agr., Dr. Prof. Adjunto, Dep. Hortic. e Silvic., Fac. Agron. UFRGS, Av. Bento Gonçalves, 7712 CEP 91501-970, Porto Alegre-RS. Bolsista CNPq. Email: pvdsouza@ufrgs.br.

${ }^{3}$ Eng. Agr., Mestrando do PPGFitotecnia, UFRGS, Dep. Hortic. e Silvic., Fac. Agron. UFRGS, Av. Bento Gonçalves, 7712 CEP 91501-970, Porto Alegre-RS. bolsista CAPES. Edgar.carniel@ufrgs.br

${ }^{4}$ Eng. Agr. Mestrando do PPGFitotecnia, UFRGS, Dep. Hortic. e Silvic. Fac. Agron. UFRGS, Av. Bento Gonçalves, 7712 CEP 91501-970, Porto Alegre-RS. Bolsista CNPq. E-mail: mariofochesato@ig.com.br.

Apoio CNPq.
} 
situada no município de Eldorado do Sul-RS. As estacas foram preparadas com 3 nós e duas folhas, com comprimento médio de $23 \mathrm{~cm}$. A base das estacas foi mergulhada em solução hidroalcoólica de ácido indolbutírico (AIB), na concentração de 1.000mg.L-1 ${ }^{-1}$ durante 10 segundos. A seguir, elas foram plantadas numa profundidade de $8 \mathrm{~cm}$, em substratos acondicionados em caixas plásticas com fundo perfurado e dimensões de $51 \mathrm{~cm}$ de comprimento, $32 \mathrm{~cm}$ de largura e $11 \mathrm{~cm}$ de altura. Cada caixa compreendeu uma parcela.

$\mathrm{O}$ delineamento experimental utilizado foi o de blocos ao acaso, com 5 tratamentos e 4 repetições, usando-se 15 estacas por parcela. Os substratos testados, que constituíram os tratamentos, foram: I) $100 \%$ vermiculita; II) $75 \%$ vermiculita $+25 \%$ casca de arroz carbonizada; III) $50 \%$ vermiculita $+50 \%$ casca de arroz carbonizada; IV) $25 \%$ vermiculita $+75 \%$ casca de arroz carbonizada, e V) $100 \%$ casca de arroz carbonizada.

O sistema de irrigação empregado foi o de microaspersão intermitente acionado por um controlador de tempo. O período de aspersão foi de 2 minutos, em intervalos de 25 minutos.

Os substratos e seus diferentes percentuais de mistura foram submetidos a análises químicas e físicas. As análises químicas de teor total de sais solúveis (TTSS) e pH em água seguiram a metodologia proposta por Röber \& Schaller (1985), adotada por Schmitz et al. (2002). As análises das características físicas, de densidade úmida, densidade seca e da curva de retenção de água, seguiram a metodologia adotada por Bellé \& Kämpf (1994).

Como parâmetros, avaliaram-se: a porcentagem de estacas vivas; o número de raízes, brotos e folhas velhas remanescentes; o comprimento das raízes e brotos por estaca, e as massas secas das raízes e brotos, obtidas pela secagem em estufa, a $65^{\circ} \mathrm{C}$, até peso constante.

As características químicas e físicas foram resultantes da média de duas amostras homogêneas das misturas. Em função disso, não foram submetidas à comparação de médias na análise estatística. Os parâmetros de desenvolvimento vegetativo foram submetidos à análise de variância e de regressão.

\section{RESULTADOS E DISCUSSÃO}

Na Figura 1A, o valor do teor total de sais solúveis aumentou à medida que o volume de casca de arroz carbonizada aumentava na mistura de cada substrato, alcançando $0,3 \mathrm{~g} . \mathrm{L}^{-1}$ na Casca de Arroz Carbonizada (CAC) pura, sendo praticamente inerte na vermiculita pura. Apesar deste comportamento, todos os valores são considerados baixos (entre 0 a $0,5 \mathrm{~g} . \mathrm{L}^{-1}$ ), segundo Conover (1967), e abaixo da faixa normal (de 1 a $2 \mathrm{~g} . \mathrm{L}^{-1}$ ), estabelecida por Röber \& Schaller (1985) para substratos hortícolas. Assim como neste estudo, Schmitz et al. (2002) também encontraram valores de TTSS próximos de $0,3 \mathrm{~g} \cdot \mathrm{L}^{-1}$ na CAC pura.

Pela Figura 1B, observa-se que o $\mathrm{pH}$ das misturas variou apenas entre 6,8 e 7,2, valores considerados levemente altos para substratos (Kämpf, 2000), cuja faixa ideal se situa entre 5,2 e 5,5. Estes valores de $\mathrm{pH}$ ficaram abaixo daqueles encontrados por Stumpf et al. (2001), sendo 7,9 para o substrato vermiculita e 9,1 para o substrato CAC. Entretanto, estas faixas de pH determinadas nestes trabalhos são características da CAC e da vermiculita (Kämpf, 2000).

$\mathrm{Na}$ Figura $1 \mathrm{C}$, os valores da densidade úmida e seca apresentaram um crescimento com a adição de CAC até a proporção de 25\% V: $75 \%$ CAC; a partir daí se estabilizaram. A diferença entre os valores da densidade úmida e densidade seca nas diferentes proporções de vermiculita e CAC confirmou a maior capacidade de retenção de água da vermiculita (Kämpf, 2000).

De acordo com Kämpf (2000), a vermiculita apresenta uma densidade seca entre 50 e $100 \mathrm{~kg} \cdot \mathrm{m}^{-3}$, estando abaixo do valor encontrado neste experimento, enquanto a CAC estaria dentro do intervalo de 150 a $250 \mathrm{~kg} \cdot \mathrm{m}^{-3}$. Também Stumpf et al. (2001) obtiveram semelhante resposta na densidade seca com estes substratos. No entanto, todos os valores de densidade seca estariam abaixo do valor de referência de 350 a $500 \mathrm{~kg} . \mathrm{m}^{-3}$ estabelecido por Conover (1967).
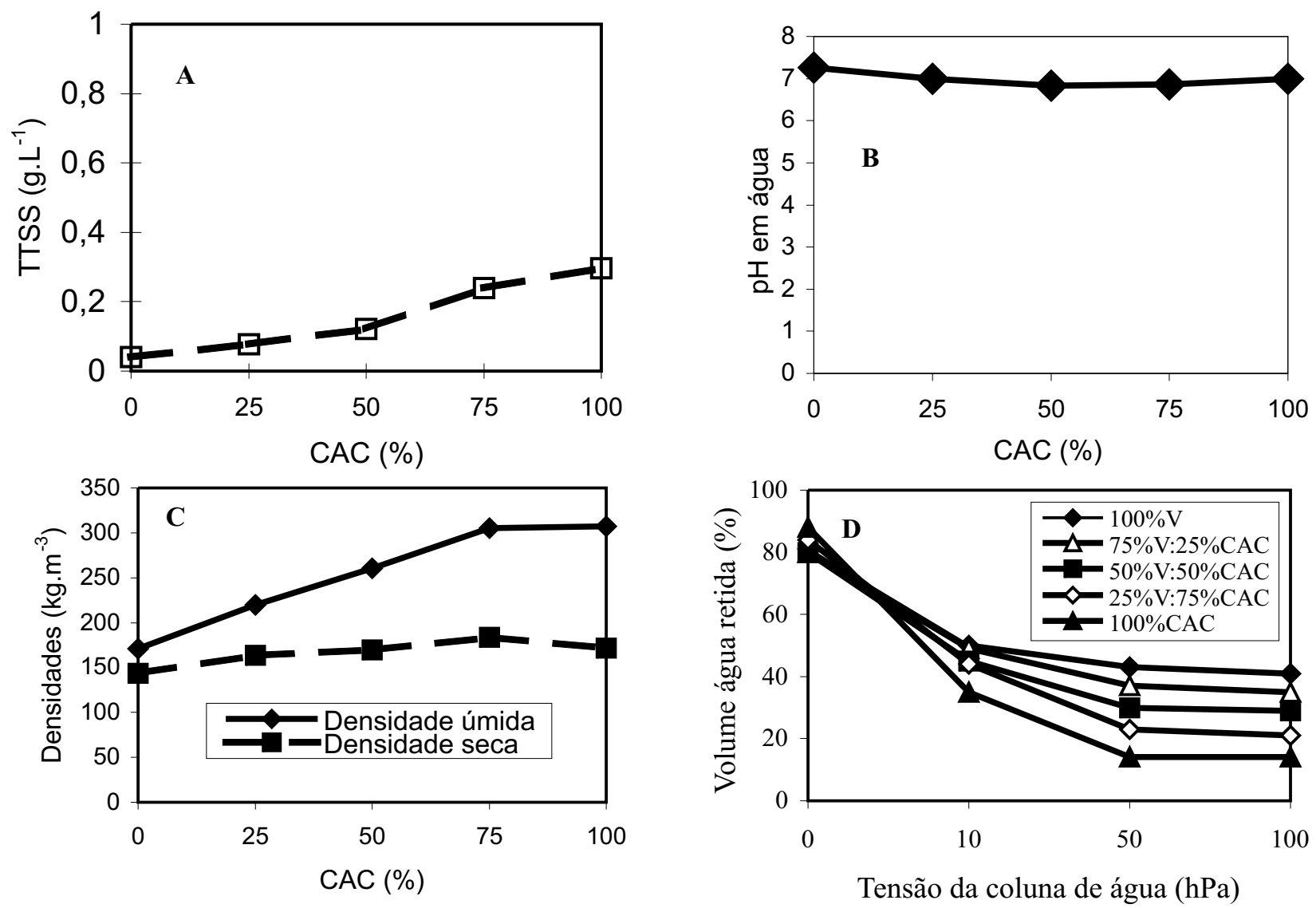

FIGURA 1 - Aspectos químicos e físicos dos substratos formados por distintas proporções de casca de arroz carbonizada (CAC) e vermiculita (V). A - Variação do teor total de sais solúveis (TTSS); B - variação do pH em água; C - Comportamento da densidade úmida e da densidade seca, e D - Curvas de retenção de água nas tensões de 0; 10; 50 e 100hPa. FA-UFRGS. Porto Alegre, 2002. 
Como neste experimento foram utilizadas caixas plásticas com grande base de apoio, a baixa densidade dos substratos não comprometeu a estabilidade do recipiente.

Na Figura 1D, encontra-se o volume de água retida através das curvas de retenção em diferentes tensões de sucção, em que a tensão zero corresponde à porosidade total, que estaria dentro do valor de referência de 80 a $90 \%$ estabelecido por Verdonck \& Gabriels (1988) para todos os substratos. Já, na tensão de 10hPa, que representa o espaço de aeração, somente o tratamento CAC $100 \%$ encontra-se entre os valores de referência de 30 a $40 \%$, referidos por Penningsfeld (1983). As demais misturas apresentam aproximadamente 50\% de volume de água retida nesta tensão.

A tensão de $50 \mathrm{hPa}$ compreende a quantidade de água disponível, com valores de referência de 24 a $40 \%$ (De Boodt \& Verdonck, 1972). Nesta faixa, estão os substratos 25\%V: 75\%CAC; 50\% V: 50\%CAC, e 75\% V: 25\%CAC (Figura 1D). O substrato CAC $100 \%$ está abaixo e o V 100\% está acima da faixa ideal. Na tensão de $100 \mathrm{hPa}$, referente à água indisponível às plantas, os substratos $50 \% \mathrm{~V}$ : $50 \% \mathrm{CAC}$ e $25 \% \mathrm{~V}$ : $75 \% \mathrm{CAC}$ estão dentro dos valores de referência (20 a 30\%) (De Boodt \& Verdonk, 1972). O substrato CAC $100 \%$ está abaixo e as demais misturas estão acima destes valores.

No geral, o substrato 50\% V: 50\%CAC apresentou a melhor resposta no volume de água retida, com valores muito próximos aos padrões descritos anteriormente.

Na Figura 2A, verifica-se um comportamento quadrático para percentagem de estacas vivas, com a máxima resposta ocorrendo entre 50\% V: $50 \%$ CAC e 25\% V: $75 \%$ CAC.

O número de brotos, de folhas velhas remanescentes e de raízes não variou significativamente nos diferentes substratos (Figura 2B).

O comprimento e a massa seca das raízes e dos brotos (Figuras 2C e 2D), à semelhança do verificado para a percentagem de estacas vivas, também apresentaram um comportamento quadrático, com a saturação das respostas ocorrendo nos substratos $50 \% \mathrm{~V}$ :
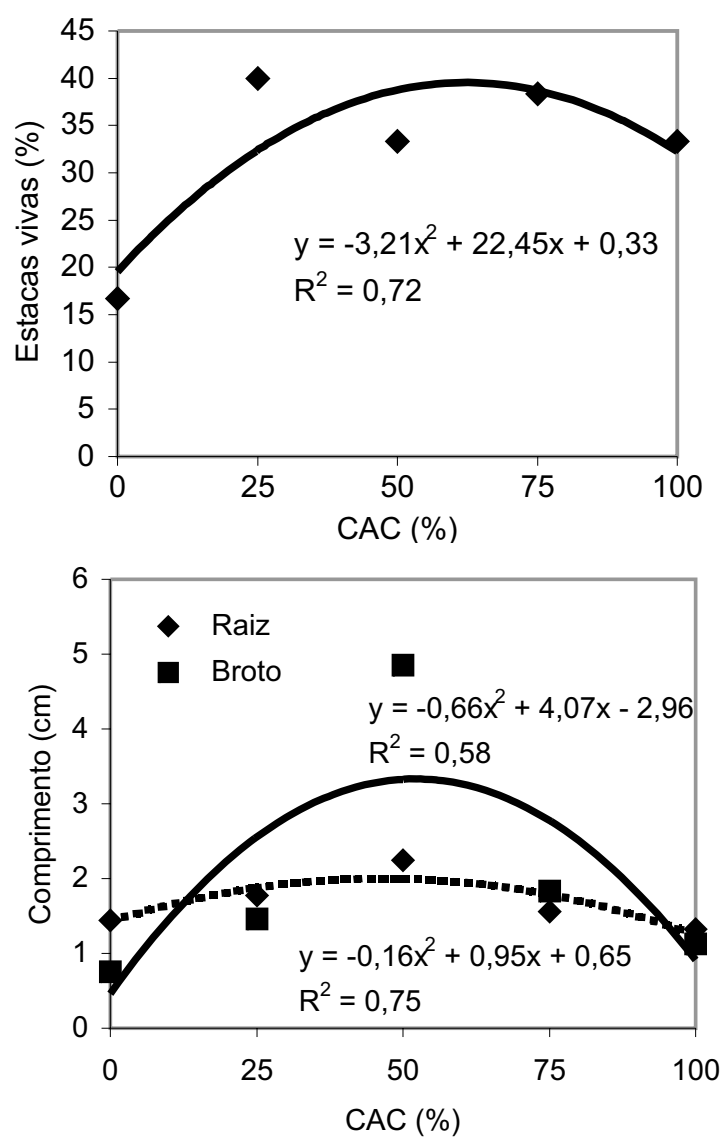

50\%CAC e 25\%V: 75\%CAC. Já, Stumpf et al. (2001) tiveram melhor formação do sistema radicular em estacas de tuia-maçã (Chamaecyparis lawsoniana Parl.) tratadas com AIB no substrato vermiculita. Também Tofanelli et al. (2003) obtiveram melhor enraizamento ao empregarem vermiculita como substrato em estacas de pessegueiro cv. 'Okinawa'. Enquanto Roberto et al. (2004), testando estacas de porta-enxertos de videira, obtiveram maior desenvolvimento radicular com a utilização do substrato CAC.

Os parâmetros de desenvolvimento vegetativo não sofreram influência das características químicas dos substratos, pois o TTSS foi significativamente baixo, e o $\mathrm{pH}$ manteve-se praticamente estável nos mesmos (Figuras 1A e 1B). O comportamento de tais parâmetros é consequiência das características físicas dos substratos (capacidade de retenção de água) atrelados ao sistema de irrigação empregado. Como neste trabalho se ministrou a mesma quantidade de água às diversas misturas, esta quantidade foi prejudicial à vermiculita isoladamente por ter, provavelmente, retido água em demasia, causando deficiência de oxigênio no substrato. Por sua vez, a CAC, por ter alta capacidade de drenagem, portanto, baixa retenção de água, deve ter provocado a desidratação das estacas, prejudicando sua sobrevivência. A mistura dos dois materiais permitiu atingirem-se níveis intermediários de retenção de água, variando a aeração e a disponibilidade de água nos substratos, favorecendo, neste regime de irrigação, a propagação do maracujazeiro. Resposta semelhante foi observada por Fermino (2003), ao trabalhar com substratos de alta e baixa capacidades de retenção de água.

Bellé (1990) propagou o maracujazeiro por sementes, testando diferentes proporções de turfa (alta capacidade de retenção de água) e CAC (baixa capacidade de retenção de água). Primeiramente, fez a semeadura em bandejas de alumínio $(15 \times 30 \times 5 \mathrm{~cm})$, obtendo maior crescimento nas plantas produzidas em substrato composto por $66 \%$ turfa: $33 \%$ CAC. Em seguida, repicou as plantas para sacos plásticos $(14,5 \times 10 \mathrm{~cm})$, obtendo melhor resposta naquelas produzidas no substrato 50\% Turfa: 50\%CAC. No presente estudo, esta também foi
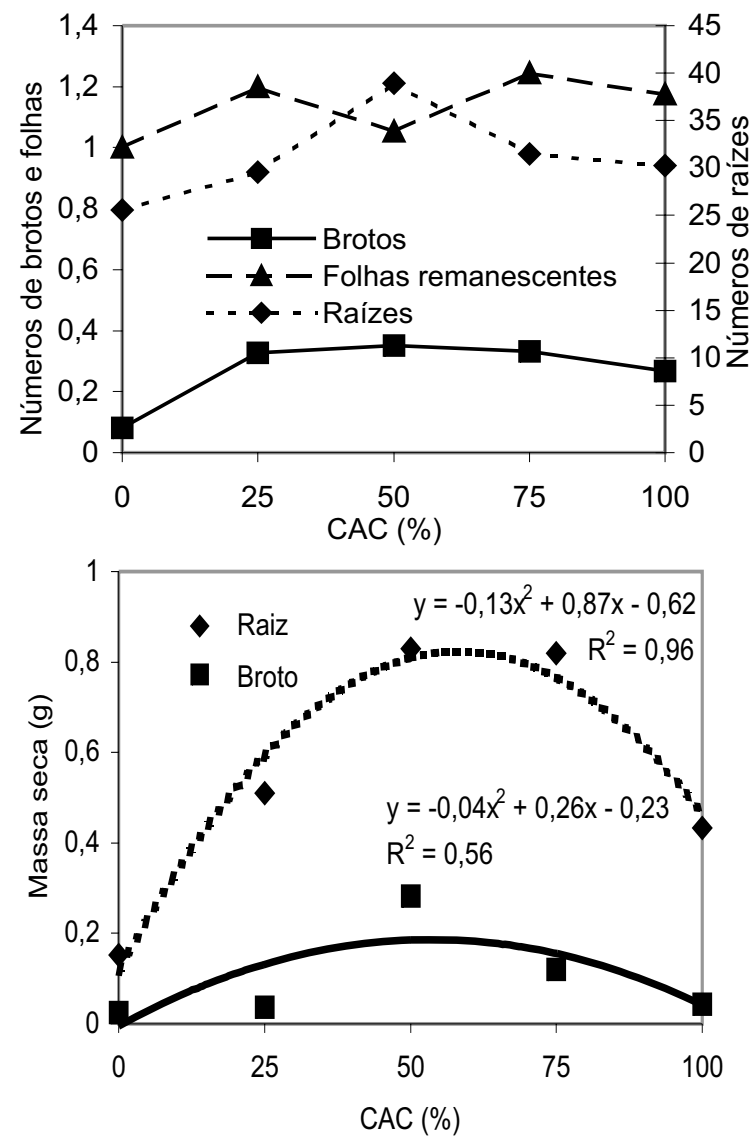

FIGURA 2 - Desenvolvimento vegetativo das estacas de maracujazeiro produzidas em diferentes proporções de substrato vermiculita (V) e casca de arroz carbonizada (CAC). A - Porcentagem de estacas vivas; B - Número de brotos, de folhas remanescentes e de raízes; C Comprimento da raiz e do broto, e D - Massa seca da raiz e do broto. FA-UFRGS. Porto Alegre, 2002. 
a mistura de materiais que promoveu o maior crescimento das plantas propagadas por estaquia.

Pelo comportamento observado neste estudo, fica patente a importância da correta escolha do substrato, visando a acelerar o desenvolvimento de mudas. Cabe destacar que, no caso de se empregar vermiculita pura para o enraizamento de estacas de maracujazeiro, o volume de irrigação deve ser menor. Já, no caso de uso de CAC pura, deve-se intensificar a freqüência da irrigação, com menor volume em cada uma.

\section{CONCLUSÕES}

Nas condições deste experimento, misturas de 50\%: $50 \%$ e 25\%: $75 \%$ de vermiculita e casca de arroz carbonizada, respectivamente, formam os melhores substratos para propagação do maracujazeiro azedo por estaquia.

\section{REFERÊNCIAS}

ALVARES, B.F et al. Influência das diluições de sacarose a solução de ácido indolbutírico na propagação do maracujazeiro (Passiflora alata Dryand). In: CONGRESSO BRASILEIRO DE FRUTICULTURA, 17., 2002, Belém. Resumos... Belém: SBF, 2002.

BELLÉ, S. Uso da Turfa "Lagoa dos Patos" (Viamão/RS) como Substrato Hortícola. 1990. 143f. Dissertação (Mestrado) Faculdade de Agronomia, Universidade Federal do Rio Grande do Sul, Porto Alegre, 1990.

BELLÉ, S.; KÄMPF, A.N. Utilização de casca de arroz carbonizada como condicionador hortícola para um solo orgânico. Pesquisa Agropecuária Brasileira, Brasília, v.29, n.8, p.1265-1271, 1994.

CONOVER, C.A. Soil amendments for pot and field grown flowers. Florida Flower Grower, Florida, v.4, n.4, p.1-4, 1967.

De BOODT, M.;VERDONCK, O. The physical properties of the substrates in horticulture. Acta Horticulturae, Wageningen, v.26, p.37-44, 1972.

FERMINO, M.H. Métodos de análise para caracterização física de substratos para plantas. 2003. 89f. Tese (Doutorado em Horticultura) - Faculdade de Agronomia, Universidade Federal do Rio Grande do Sul, Porto Alegre, 2003.

IBGE. Instituto Brasileiro de Geografia e Estatística. Disponível em: <http://www. ibge.gov.br>. Acessado em: 23 fev.2005.
JUNQUEIRA, N.T.V. et al. Produção de mudas de maracujá-azedo por estaquia em bandejas. Planaltina: Embrapa Cerrados. 2001. 3p. (Recomendação Técnica, 42).

KÄMPF, A.N. Seleção de materiais para uso como substrato. In: KÄMPF, A.N.; FERMINO, M.H. (Ed.). Substratos para plantas: a base da produção vegetal em recipientes. Porto Alegre: Gênesis, 2000. p.139-145.

OLIVEIRA, J.A.de et al. Efeito dos substratos artificiais no enraizamento e no desenvolvimento de estacas de maracujazeiroazedo (Passiflora edulis Sims f. flacicarpa Deg). Revista Brasileira de Fruticultura, Jaboticabal, v.24, n.2, 2002. Disponível em: <http://www.scielo.com.br>. Acessado em: 4 nov.2005.

PENNINGSFELD, F. Kultursubstrate fur den gartenbau, betschland: ein kritischer Überblick. Plant and Soil, The Hague, v.75, p.269281, 1983.

RÖBER, R.; SCHALLER, K. Pflanzenernährung im gartenbau. Stuttgart: Ulmer, 1985.352p.

ROBERTO, S.R. et al. Avaliação do enraizamento de pâmpanos de porta-enxertos de videira em diferentes substratos avaliados mediante imagens. Acta Scientiarum: Agronomy, Maringá, v.26, n.1, p.85-90, 2004.

SCHMITZ, J.A.K. et al. Propriedades químicas e físicas de substratos de origem mineral e orgânica para o cultivo de mudas em recipientes. Ciência Rural, Santa Maria, v.32, n.6, p.937-944, 2002.

SILVA, F. M. et al. Enxertia de mesa de Passiflora edulis Sims f. flavicarpa deg. sobre Passiflora alata Curtis, em ambiente de nebulização intermitente. Revista Brasileira de Fruticultura, Jaboticabal, v. 27, n. 1, p. 98-101, 2005.

STUMPF, E.R.T. et al. Efeito do ácido indolbutírico, substrato e tipo de estaca no enraizamento de Chamaecyparis lawsoniana Parl. Revista Brasileira de Agrociência, Pelotas, v.7, n.2, p.101-105, 2001.

TOFANELLI, M.B.D. et al. Enraizamento de estacas lenhosas de pessegueiro cv. Okinawa em diferentes diâmetro de ramos, substratos e recipientes. Ciência Rural, Santa Maria, v.33, n.3, p.437-442, 2003.

VERDONCK, O.; GABRIELS, R. Substrate requirements for plants. Acta Horticulturae, Wageningen, v.221, p.19-23, 1988. 